(a)
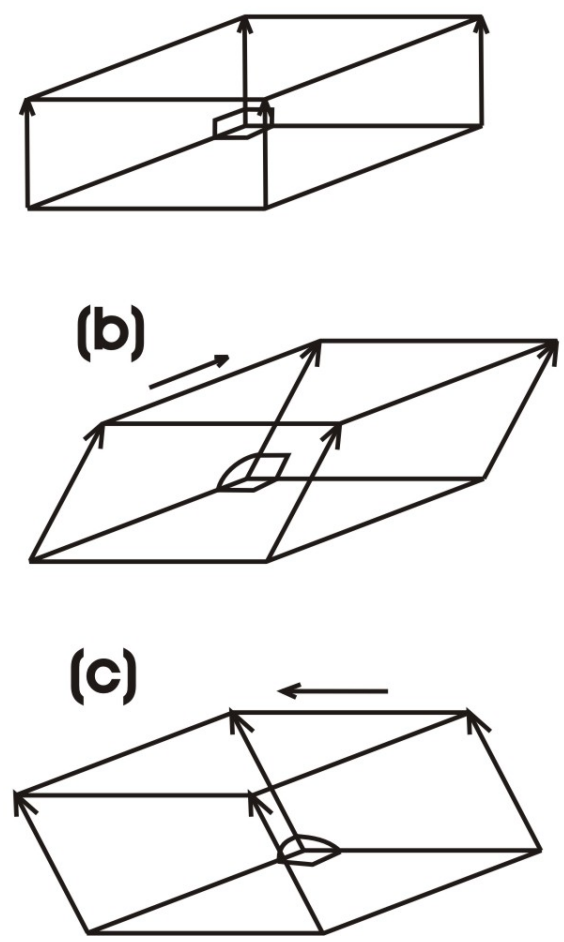

Figure 1. Formation of the biclinic parallelepiped. (a): orthorhombic parallelepiped, (b):monoclinic parallelepiped, (c): biclinic parallelepiped.

Keywords: crystal system, space group, formulae, kaolinite

\section{MS15-P23 Crystal Structure of a New Coordination Polymer}

Hamadene Malika ${ }^{1}$, Benhacine Mohamed El-Amin ${ }^{1}$, Bouacida Sofiane $^{2}$, Merazig Hocine ${ }^{2}$

1. Laboratoire de Cristallographie-Thermodynamique, Faculté de Chimie, U.S.T.H.B, Alger, Algérie

2. Unité de Recherche de Chimie de l'Environnement et Moléculaire Structurale, Faculté des Sciences Exactes, Université des frères Mentouri, Constantine 1, 25000, Algérie

\section{email: hamadene.m21@gmail.com}

The oxalate dianion is one of the most studied ligands, capable of bridging two or more metal centres and creating inorganic polymers based on the assembly of metal polyhedra with a wide variety of one-, two - or three dimensional extended structures. Among the oxalate-based compounds $\mathrm{M}$ with the general formula $\mathrm{AM}\left(\mathrm{C}_{2} \mathrm{O}_{4}\right) \cdot \mathrm{n}\left(\mathrm{H}_{2} \mathrm{O}\right) \quad(\mathrm{A}=$ alkali metal and , $\mathrm{M}=$ trivalent element), only a few crystal structures involving sodium metal have been reported in the literature with $\mathrm{M}=\mathrm{Yb}$ $[1]<$. As a continuation of work on mixed oxalate-based compounds with a tri- or bivalent element [2] a new coordination polymer, namely catena-poly[[ diaquasodium(I)]- $\mu$-oxalato- $\mathrm{k}^{4} \quad \mathrm{O} 1, \mathrm{O} 2: \mathrm{O} 1$ ',O2' -[diaquairon(III)]- $\mu$-oxalato- ${ }^{4} \mathrm{O} 1, \mathrm{O} 2: \mathrm{O} 1$ ',,${ }^{\prime}$ '] $\left[\mathrm{NaFe}\left(\mathrm{C}_{2} \mathrm{O}_{4}\right)_{2}\left(\mathrm{H}_{2} \mathrm{O}\right)_{4}\right]_{n}$, has been prepared and its crystal structure elucidated by single-crystal X-Ray diffraction analysis [3]. The compound crystallizes in the non centrosymmetrical space group $I_{1}(Z=4)$. The asymmetric unit contains one $\mathrm{Na}(\mathrm{I})$ atom and one $\mathrm{Fe}(\mathrm{III})$ atom lying on a fourfold symmetry axis, one oxalate ligand and two aqua ligands. Each metal atom is surrounded by two chelating oxalate ligands and two equivalent water molecules, in a cis arrangement. The structure consists of infinite one-dimensional chains of alternating $\mathrm{FeO}_{4}\left(\mathrm{H}_{2} \mathrm{OW} 1\right)_{2}$ and $\mathrm{NaO}_{4}\left(\mathrm{H}_{2} \mathrm{OW} 2\right)_{2}$ octahedra, bridged by oxalate ligands, parallel to the [100] and [010] directions, respectively (Fig. 1). Because of the cis configuration and the $\mu_{2}$-coordination mode of the oxalate ligands, the chains run in a zigzag manner. This arrangement facilitates the formation of hydrogen bonds between neighboring chains involving the $\mathrm{H}_{2} \mathrm{O}$ and oxalate ligands, leading to a two-dimensional framework. The resulting framework exhibits tunnels parallel to the $\mathrm{c}$ axis with an elliptic cross-section as shown in Fig. 1. The structure of this new one dimensional coordination polymer is shown to be unique among the $\mathrm{A}^{\mathrm{I}} \mathrm{M}^{\mathrm{III}}\left(\mathrm{C}_{2} \mathrm{O}_{4}\right)_{2}\left(\mathrm{H}_{2} \mathrm{O}\right)$ series. The thermal decomposition behavior has been studied by TG and DTA and gave as a final product the well-known ternary oxide $\mathrm{NaFeO}_{2}[1]$ Chapelet-Arab B., Duvieubourg, L., Nowogrock1 ${ }^{2}$ G., Abraham F., Grandjean S. (2006). J. Solid State Chem. 179, 4029 [2] Kherfi H., Hamadène M., Guehria A., Dahaoui S. \& LecomteC. (2011). Acta Cryst. C67, m85 (2013). Acta Cryst. E69, m493 [3]Benhacine M.A., Hamadène M., Bouacida S., Mérazig H. (2016). Acta Cryst. C72, 243

Keywords: absolute structure, one-dimensional chains, new structural type 